\title{
Aprendizagem na Educação a Distância: Caminhos do Brasil ${ }^{1}$
}

\author{
Sérgio Roberto Kieling Franco \\ Faculdade de Educação - Universidade Federal do Rio Grande do Sul \\ Av. Paulo Gama, s/n ${ }^{\circ}$ prédio $12.201-7^{\circ}$ andar \\ Porto Alegre - RS - CEP 90046-900 \\ (51) 3316-3428 - sergio.franco@ufrgs.br \\ Luciano Andreatta Carvalho da Costa \\ Núcleo de Educação a Distância - Universidade Estadual do Rio Grande do Sul \\ Av. Sete de Setembro, 1156 - Porto Alegre - RS - CEP 90010-191 \\ (51) 3288-9000 - lucianocarvalhodacosta@gmail.com \\ Rute Vera Maria Favero \\ Escola Técnica - Universidade Federal do Rio Grande do Sul \\ Rua Ramiro Barcelos, 2777 - Porto Alegre - RS - CEP 90035-007 \\ (51) 3316-5110 - rutevera@escolatecnica.ufrgs.br

\section{Lilian Schwab Gelatti} \\ Faculdade de Educação - Universidade Federal do Rio Grande do Sul \\ Rua Roque Gonzales, 145/401 - Porto Alegre - RS - CEP 90690-270 \\ (51) 3336-5368-liliangelatti@gmail.com \\ Ederson Luiz Locatelli \\ Universidade do Vale do Rio dos Sinos \\ R. Aloysio Sehnen, 186 - Cristo Rei - São Leopoldo - RS \\ (51) 3590-4884- locatellisj@gmail.com
}

Resumo. Este artigo descreve o projeto de pesquisa "Aprendizagem na Educação a Distância: Caminhos do Brasil", aprovado pelo CNPq, que tem como objetivo conhecer as concepções de aprendizagem que embasam a produção científica buscando constituir um quadro teórico das iniciativas em EAD no Brasil.

Palavras Chave: Educação a Distância, Aprendizagem, Conhecimento

\section{Learning in the Distance Education: Roads of Brazil}

Abstract. The present article describes a research project supported by CNPq named "Aprendizagem na Educação a Distância: Caminhos do Brasil". Its main aim relies in knowing the learning concepts that have based the scientific production in Brasil in the field of Distance Education.

Keywords: Distance Education, Learning, Knowledge

\section{A EDUCAÇÃO A DISTÂNCIA NO BRASIL}

A educação a distância é uma prática educativa que já está consolidada no mundo ocidental há quase um século. No Brasil, as iniciativas de educação a distância também não são novidade. Desde a década de 1920, há registros de práticas educativas a distância. 
O que diferencia o Brasil de outros países é que, aqui, a educação a distância ficou por muito tempo restrita a iniciativas de educação supletiva ou de formação profissional de nível básico. Por muito tempo vigorou uma falsa crença de que não se poderia fazer ensino regular a distância.

Enquanto na segunda metade do século $\mathrm{XX}$, vários países, em todos os continentes lançaram mão da educação a distância como forma de ampliar a formação de profissionais técnicos e mesmo a formação superior, permaneceu a resistência brasileira. Várias podem ser as explicações para esta resistência. Fatores de ordem cultural (um país de tradição oral), de ordem política (inovações pedagógicas incentivadas pelo governo militar eram vistas como formas de dominação e concretização do imperialismo norte-americano), entre outras. Ainda que seja difícil determinar quais as causas, é evidente que ocorreu um fenômeno de represamento da educação a distância no Brasil.

Esse cenário começa a se modificar a partir dos anos 1990. A nova lei de Diretrizes e Bases da Educação Nacional, aprovada em 1996, dedica o artigo 80 à educação a distância, além de citá-la em vários outros artigos. No mesmo ano, o Ministério da Educação institui a Secretaria de Educação a Distância, em sua estrutura interna.

Em 1998 surge a primeira regulamentação para cursos a distância (Decreto 2494/98, modificado em parte pelo Decreto 2561/98), abrangendo o ensino médio, a educação profissional e a educação superior. Este decreto foi substituído pelo Decreto 5622 , de dezembro de 2005, tornando as regras mais claras e prevendo a educação a distância em todos os níveis e modalidades da Educação Nacional, como preconiza a LDB.

Entre 1998 e 2005 houve um grande incremento da oferta de cursos a distância e a academia passou a olhar o tema também de forma científica. Isso fica demonstrado na quantidade de teses produzidas nas universidades brasileiras a respeito do assunto. Constam no banco de teses da CAPES 219 teses que têm como palavra-chave a Educação a Distância ou Ensino a Distância, sendo a sua maciça maioria produzida entre 1998 e 2005.

Isso indica o crescimento da educação a distância no Brasil. Tal crescimento está também relacionado ao avanço das tecnologias de informação e comunicação - TIC's, que possibilitou trazer certas vantagens do ensino presencial para a situação a distância. Este incremento da educação a distância traz consigo uma grande preocupação quanto à qualidade dos processos educativos. Esta preocupação que tem alimentado, em parte, a resistência das faculdades de Educação das universidades brasileiras.

\section{A EDUCAÇÃO A DISTÂNCIA E AS TEORIAS SOBRE APRENDIZAGEM E CONHECIMENTO}

A Educação a Distância é um fenômeno da Idade Contemporânea, que surge muito ligada à Era Industrial (Peters, 2001b). Os primeiros registros de uma educação sistemática, ministrada a distância, datam do século XIX. Poderíamos dizer que ela nasce em um contexto de modernidade ascendente.

O desenvolvimento científico e tecnológico ia em ritmo acelerado. Era latente a sensação de que, em breve, o homem (era o homem e, não o ser humano, não o homem e a mulher) chegaria a desvendar todos os mistérios da natureza. 
É claro que já havia os que apontavam para os perigos dessa ilusão. Foi nesse contexto que Sören Kierkgaard cunhou a palavra "angústia" que expressava a sensação humana de estar à beira de um abismo. Um abismo que veio se apresentar logo no início do século XX, nas duas grandes guerras, seguido pela ameaça nuclear, pelo recrudescimento de regimes autoritários, pelo escancaramento (muito devido ao aumento do poder de comunicação da humanidade, graças ao desenvolvimento tecnológico) das misérias humanas da fome, da exploração sexual, da exploração do trabalho, das subjugações ideológicas de todas as cores. É neste contexto que nasce e se desenvolve a educação a distância.

O desenvolvimento industrial, a necessidade de formar melhor os quadros para a indústria. A realidade dos países destruídos pelas guerras, exigindo formação de pessoal para sua reconstrução. A necessidade de criar identidades nacionais, especialmente em países de territórios continentais. Tudo isso se constituía em um solo fértil para o desenvolvimento da educação a distância.

No entanto, é preciso ter em conta mais um fator. A Modernidade se constitui pela afirmação da racionalidade, pela possibilidade do conhecimento. Conhecimento este transformador da realidade, seja pela tecnologia, seja pela ideologia.

Essa forma moderna de lidar com a racionalidade traz junto consigo uma mudança radical no modo de encarar o processo educativo. A Universidade deixa de ser um espaço de troca de idéias, de debates entre teses (formato original da Universidade) e passa a ser predominantemente espaço de formação profissional, dando-se esta, basicamente pela transmissão de informações (confundidas com o conhecimento) de forma a tornar as novas gerações aptas a desempenhar as funções que a sociedade necessitava.

Não havia mais lugar para a discussão teológica e filosófica. Era necessário formar engenheiros, médicos, advogados, cientistas, e depois, psicólogos, economistas, administradores, etc. Isso se dava pela transmissão do conhecimento. Não pela transmissão de "verdades canônicas", eternas, mas pela transmissão de verdades científicas, e, por isso, eternas.

Neste contexto ensinar é transmitir. E se é só isso, por que atrelar o ensino à presença do professor? Estava aberto o caminho para os processos de ensino a distância.

Aos poucos a experiência foi mostrando que quando essa transmissão não contava com a participação direta do professor, era necessário dar um tratamento especial à linguagem que veiculava essa transmissão. Surgem, então, estudos para aperfeiçoamento do material didático (chamado "material instrucional").

A Humanidade estava vivendo nessa época o momento áureo da Psicologia como ciência do comportamento humano. Como a ciência moderna se desenvolvera para o ser humano poder controlar o mundo (interpretação moderna do "crescei, multiplicai-vos e dominai a terra" - Gen 1,28 ), a Psicologia tornou-se a possibilidade de controlar o comportamento.

Neste momento Psicologia e Educação se dão as mãos (surgem a Psicologia da Aprendizagem e a Psicologia da Educação), pois se entendia também que educar é controlar (herança da disciplina mental de La Salle, apesar dos brados de Rousseau). Portanto era o momento de aproveitar as ferramentas (e os argumentos) que a Psicologia fornecia. 
Skinner (talvez o maior psicólogo norte-americano do século XX) vinha afirmar que o professor não só era dispensável, como também era um mau instrumento de ensino. Seu argumento fundava-se no fato de o professor, historicamente, trabalhar com grupos de alunos, não podendo acompanhá-los individualmente. Para esse autor a possibilidade de ensinar adequadamente, isto é, de modelar o comportamento do aluno exigia que esse aluno fosse tratado individualmente. E o professor, sendo um só, e centralizando a ação de ensinar na sua pessoa, não possibilitava essa situação individualizada.

É interessante assinalar que, ao contrário do que parece ao senso comum educacional, a idéia do ensino individualizado é de cunho empirista. E o movimento behaviorista (que na Educação foi reconhecido como "tecnicista") tinha como "pedra de toque" exatamente a individualização do ensino.

Claro que quando se considera o conhecimento como originado do exterior, a tendência é se desvalorizar o sujeito. E na psicologia behaviorista não era diferente. $\mathrm{O}$ sujeito, apesar de operante (na visão do neobehaviorismo skinneriano), era visto como um ser moldável, bastando controlar-se as contingências de reforço. Portanto essa apologia do ensino individualizado não era no sentido de dar ao indivíduo oportunidade para manifestar-se e traçar seu próprio caminho, mas de condicionar-lhe a contento. Modificar o comportamento de um modo mais eficaz, atingindo, portanto, melhor os objetivos educacionais.

Foi Skinner, um dos principais propositores do uso de aparatos tecnológicos, que preconizava que estes aparatos conferiam mais eficácia ao ensino. Suas famosas "máquinas de ensinar" foram, de certo modo um dos precursores do computador (pelo menos no seu uso educacional).

Tendo todo esse ambiente teórico favorável e ainda com o desenvolvimento dos meios de comunicação eletrônicos (rádio e televisão) a educação a distância ganha um novo impulso. Melhoraram as possibilidades de transmissão do conhecimento.

Ao mesmo tempo que a concepção de que ensinar é transmitir conteúdos ia se estabelecendo como hegemônica, foram surgindo os movimentos contra-hegemônicos. $\mathrm{Na}$ área da Educação o movimento mais forte contra a "avalanche" tecnicista, foi o movimento conhecido como Humanismo. Seu principal representante foi Carl Rogers, psicólogo norte-americano que, inspirado em ideais humanistas e cristãos, bem como pela visão de mundo liberal (laissez faire, laissez passer), vem propor uma pedagogia centrada no aluno, com uma interpretação claramente apriorista.

Esse pensamento rogeriano obteve muita repercussão nos movimentos pedagógicos contra-hegemônicos. Espalharam-se no mundo todo experiências não diretivas de Educação. Assim, contrapondo-se à (provavelmente) fictícia comunidade Walden II (Skinner, 1978), surgia uma real escola de Summerhill (Neill, 1976).

Atualmente uma visão psicológica que tem conseguido muita projeção é o Cognitivismo Norte-americano, e que não rompeu com a tradição positivista. Trata-se de uma visão linear, às vezes tentando dar uma certa dinamicidade em suas análises, mas que não consegue superar a dicotomia entre o "de dentro" e o "de fora", permanecendo presa a conceitos importantes nesta óptica como input e output, seguindo a tradição cartesiana de ver o ser humano como uma máquina. Não mais um mecanismo (seguindo as leis da mecânica), mas um circuito muito complexo, como um computador de alto padrão (Cf. Eysenck \& Keane, 1994). 
Essa escola, ao contrário dos behavioristas clássicos, insiste no fato de que a relação entre input e output não é direta, que há um processamento da informação no meio do caminho. Não temos agora somente estímulo e resposta, mas entre os dois encontramos a "mediação" do processamento. Na educação a distância tal movimento também encontra ressonância.

Fazendo frente à acusação de que educação a distância é mero método de instrução, que torna o aluno simplesmente um receptor de conteúdos, as principais universidades a distância, criadas a partir do final da década de 1960, passaram a incorporar no seu discurso uma concepção humanista. Passaram a enfatizar que educação a distância é uma experiência de auto-aprendizagem, que todo o processo de ensino-aprendizagem estava centrado no aluno (Peters, 2001A; Aretio, 2001). Curiosamente, mesmo após a derrocada das experiências pedagógicas humanistas, o discurso da educação a distância continua fortemente calcado nessa concepção.

A partir das contribuições de teóricos como Piaget, Vygotsky, Paulo Freire, foi possível encontrar argumentos fortes para superar a visão simplista, tanto de que aprendizagem é simplesmente mudança de comportamento, quanto de que ela está garantida pela motivação a auto-iniciativa do aluno. Ora, o que os autores que foram citados acima apontam é a importância de um processo de interação.

O processo de construção do conhecimento ocorre devido à interação do sujeito com o que ele conhece. Isso significa que, se por um lado o conhecimento não está garantido pela simples transmissão de informações, por outro, não se pode, ingenuamente, partir do princípio de que a simples motivação ou disposição para aprender garantem o aprendizado. Tanto a disposição do sujeito como a forma como o conhecimento aparece para ele (exposição, videoconferência, apostila, objeto de aprendizagem) são fatores a serem considerados. Mas o problema não termina por aí. $\mathrm{O}$ conhecimento também não é fruto somente da justaposição do que o sujeito traz com o que é apresentado a ele. É sempre uma construção nova, uma nova interpretação que o sujeito faz a partir do que trouxe consigo, da significação (lógica e intuitiva) que o sujeito deu à realidade com a qual se defronta. E este processo é essencialmente um processo ativo.

Dentro da perspectiva da Epistemologia Genética (a teoria de Piaget), a aprendizagem é uma das formas de aquisição de conhecimentos, que pode gerar uma construção de conhecimento ou não.

O que possibilita essa diferenciação é a abordagem dialética feita por essa teoria. Pretende-se dizer com isso que só é possível conceber a construção do conhecimento distintamente da aprendizagem se a análise dos processos cognitivos se der a partir de uma visão dinâmica, e de uma visão da realidade como uma rede de relações que envolve esses processos.

Não há espaço aqui para entrar em maiores pormenores, mas é importante ressaltar que as abordagens de Vygotsky e Maturana, entre outros, caminha na mesma direção. As explicações são diversas, mas abordam a aprendizagem como processo dinâmico e interativo, sem destaque nem para os elementos externos, nem para os internos, mas sim da relação (interação) entre tais elementos.

Como já fora apontado acima, chama a atenção, que, mesmo com todo esse desenrolar dos debates sobre a compreensão do processo de conhecimento e de aprendizagem, quando se analisa a bibliografia internacional sobre educação a distância nos defrontamos com um fenômeno interessante. Os argumentos utilizados pelos 
autores consagrados contra uma pedagogia instrucionista na educação a distância trazem à tona a discussão (já superada) que foi travada nas décadas de 60 a 80 no cenário educacional. Trata-se praticamente de uma reedição dos consagrados debates entre Rogers e Skinner, que discutiam a autonomia ou não do estudante e sobre o papel do professor, se devia ser diretivo ou liberal.

Daí se pode depreender que a discussão pedagógica no cenário da educação a distância é uma discussão muito primária, ou seja, uma discussão distante do cenário atual das discussões educacionais. caminho?

Será que a produção brasileira sobre educação a distância está no mesmo

Educação a distância pode ser uma inovação pedagógica, principalmente a partir do desenvolvimento das TIC's. O desafio é que não seja somente uma inovação tecnológica (como a substituição do quadro-negro pela tela do computador ou da explicação oral do professor pelo uso de uma animação computadorizada).

Por isso cabem as perguntas: como a pesquisa brasileira, sobre educação a distância, tem abordado o fenômeno da aprendizagem?

Com que perspectiva teórica? A partir de que abordagem? Portanto, a presente pesquisa tem o seguinte problema central: que concepções de aprendizagem embasam as teses de doutorado produzidas no Brasil entre 1998 e 2005 ?

Esta pesquisa constitui-se em um passo importante dentro de uma série de outras que visam contribuir para uma efetiva avaliação do quadro da educação a distância no Brasil, bem como a proposição de formas de se fazer educação a distância.

\section{SITUAÇÃO ATUAL DA PESQUISA}

A pesquisa está no início de sua realização, por isso encontramo-nos nos primeiros itens assinalados em itálico do cronograma abaixo: levantamento das teses, busca de arquivos digitais, contato com as instituições, criação de um Banco de Dados (BD) e o estabelecimento das categorias, que passamos a relatar a seguir.

Cronograma de Atividades

1. Levantamento das teses existentes no Banco de Teses CAPES (2006);

2. Procura por arquivos digitais das teses na internet (2006);

2 3. Contato com as instituições com vistas a conseguir cópias ou empréstimo das teses a serem estudadas (2006).

4. Criação de um BD para armazenamento de todas as informações coletadas (2006).

3 5. Estabelecimento das categorias para realizar a triagem (2006).

6. Triagem das teses que tratam sobre aprendizagem (2006/2007).

7. Leitura e análise da fundamentação teórica das teses triadas.

8. Leitura e análise das conclusões das teses triadas.

9. Confrontação entre a fundamentação teórica e a conclusão de cada tese.

10. Elaboração do relatório final. 
11. Elaboração de artigos a serem submetidos em congressos (nacional e internacional).

Tão logo o grupo de pesquisa, representado por alguns membros neste artigo, organizou-se para dar início ao trabalho, fez-se uma busca de teses no banco de teses da CAPES, cuja base de dados oferece a possibilidade de busca para os seguintes campos: autor, assunto, instituição, nível/ano base (opcional).

Para a busca da pesquisa (compreendendo todas as teses de 1998 a 2005) foi utilizado o termo "Educação a distância" e "Ensino a distância" no campo "assunto como termo exato" e nível de pesquisa "Doutorado".

Cabe esclarecer que como o banco de dados da CAPES aceita acentuação, os termos para a nossa busca foram: "Educação a distância", "Educação à distância", "Educação à distancia", "Educação a distancia", "Ensino a distância", "Ensino a distancia", "Ensino à distância" e "Ensino à distancia". Para cada termo houve um total de teses encontradas, sendo que algumas se repetiam.

Esta foi a primeira busca, totalizando 117 teses. Após conferirmos a busca novamente, demos início a uma triagem. Esta triagem foi feita com uma análise mais detalhada verificando se a tese é de fato sobre educação a distância. Caso contrário, deveria ser eliminada da pesquisa. As teses que passaram na triagem sofreram uma nova triagem, desta vez, com a palavra-chave "aprendizagem" o que nos deu o número de 110 teses - presente objeto de pesquisa desta investigação.

Em virtude de as teses terem começado a ser disponibilizadas em rede, somente a partir de 2001, estamos realizando a busca dos arquivos digitais disponíveis na internet, seja nos bancos de tese das bibliotecas, seja em páginas pessoais, seja em outros sítios eletrônicos de hospedagem. A biblioteca da UFRGS tem-se mostrado bastante solidária nesta tarefa.

Para fins de coleta de dados, estamos, concomitantemente, criando um BD, a fim de que todas as informações catalogadas sejam acessadas com uma maior agilidade, tanto no momento de cadastramento, como no de consulta.

$\mathrm{O}$ acesso ao $\mathrm{BD}$, sediado em um servidor dentro da própria instituição, será feito através da internet e com senha. O front-end do sistema de acesso ao banco de dados será desenvolvido na linguagem PHP, e o gerenciador de banco de dados será o MySQL. A instituição oferece a possibilidade de usar software proprietário ou software livre. Optamos pelo uso do software livre por ser de fácil acesso, fácil manuseio, fácil manutenção e de fácil gerenciamento.

O BD guardará a data de solicitação das teses ao autor/instituição, a resposta obtida, a data de recebimento das teses e o meio em que o envio foi realizado: digital ou impresso.

Além destas informações, serão armazenados dados sobre: 1) autores, 2) teses, 3) autores referenciados, a fim de averiguar uma consistência entre autores e teorias mencionadas, e, 4) a avaliação do pesquisador/leitor sobre a tese lida, estabelecendo se a mesma continuará a fazer parte da pesquisa ou não. Como, cada tese, será lida por dois pesquisadores e, se necessário por um terceiro, foi gerada uma tabela para armazenar os dados referentes às impressões de três leitores. 
As categorias foram estabelecidas partindo-se das teorias de aprendizagem Empirista, Apriorista e Interacionista, buscando saber como o processo de aprendizagem foi descrito em cada tese e assim ter uma visão de como a EAD está sendo vista pelos 'estudiosos' do assunto. Com a leitura das teses, poderão surgir novas categorias ou algumas das existentes poderão ser excluídas.

\section{PERSPECTIVA E FUTUROS DESAFIOS}

A próxima atividade a ser realizada será a leitura "diagonal" que cada pesquisador fará de uma tese, na tentativa de identificar se as categorias estabelecidas suprem as necessidades dessa pesquisa. Levando-se em consideração os aspectos apresentados na seção 2, o que será peremptório para se determinar se uma tese tem um cunho interacionista? Vários aspectos podem ser considerados, como os autores citados, o tipo de metodologia utilizada, se foi realizada ou não uma experimentação com alunos, etc. Esta atividade envolverá a necessidade de uma discussão aprofundada, pois estes critérios determinarão os próximos rumos da pesquisa.

Após a "autenticação" das categorias, as teses serão lidas integralmente por, no mínimo, dois avaliadores, que farão o registro das categorias encontradas em cada tese; caso estas sejam discordantes, a mesma será avaliada por mais um pesquisador.

Como fim último, nossa preocupação é contribuir para que a educação a distância venha a se constituir efetivamente em uma inovação pedagógica, e que auxilie na própria reflexão do fazer pedagógico em geral (presencial ou a distância, com o uso de tecnologias avançadas ou não). Afinal, a Educação é um fenômeno humano (da humanidade) e é nesta perspectiva que dever ser abordada e praticada.

${ }^{1}$ O projeto de pesquisa "Aprendizagem na Educação a Distância: Caminhos do Brasil" está sendo financiado pelo CNPq.

\section{REFERÊNCIAS BIBLIOGRÁFICAS}

ALMEIDA, F. \& FONSECA J, Moraes F. Proinfo: projetos e ambientes inovadores. Brasília: Ministério da Educação, 2000.

ARETIO, L. G. La educación a distancia: de la teoria a la práctica. Barcelona: Ariel, 2001.

BECKER, F \& FRANCO, S. R. K. (orgs.) Revisitando Piaget. Porto Alegre, Mediação, 1998.

BECKER, F. A epistemologia do professor: o cotidiano da escola. 7. ed. Petrópolis: Vozes, 1999.

BELLONI, M. L. Educação a distância. Campinas: Autores Associados, 1999.

BIGGE, M.L. Teorias da aprendizagem para professores São Paulo: EPU, 1977.

BRITO, E.P.P. Uma leitura de políticas de educação a distância no Brasil: da radiodifusão à televisão educativa. Porto Alegre: UFRGS. 2003. Tese de Doutorado.

CAMPOS, F. e outros. Cooperação e aprendizagem on-line Rio de Janeiro: DP\& ${ }^{\mathrm{a}} \mathrm{A}$, 2003. 
CARVALHO-DA-COSTA, L. A. A avaliação da aprendizagem no ensino de estruturas: epistemologia, tecnologia e educação a distância. Porto Alegre: Universidade Federal do Rio Grande do Sul. 2004. Tese de Doutorado.

DACOREGGIO, M. dos S. Ação docente: uma ação comunicativa, um olhar para o ensino superior presencial e a distância. Florianópolis: Edição da autora, 2001.

DANIEL, J. Educação e tecnologia num mundo globalizado. Brasília: UNESCO, 2003.

ELIASQUEVICI, M. K. \& FONSECA, N. A. da Educação a distância: orientações para o início de um percurso. Belém: EDUFPA, 2004.

EYSENCK, M. W. \& KEANE, M. T. Psicologia cognitiva: um manual introdutório. Porto Alegre: Artmed, 1994.

FLICKINGER, H. \& NEUSER, W. Teorias de auto-organização: as raízes da interpretação construtivista do conhecimento. Porto Alegre: EDIPUCRS, 1994.

FRANCO, S. R. K.(org.) Educação a distância na Universidade Federal do Rio Grande do Sul. Porto Alegre: UFRGS, 2004.

FRANCO, S.R. K. (org.) Informática na educação: estudos interdisciplinares. Porto Alegre: UFRGS, 2004.

FRANCO, S.R. K. O construtivismo e a educação. 6. ed. Porto Alegre: Mediação, 1997.

JAMBEIRO, O. \& RAMOS, F. Internet e educação a distância. Salvador: EDUFBA, 2002.

KIERKEGAARD, Soren A. O Conceito de Angústia. Trad. T. Guimarães, São Paulo: Hermus, 1968.

MARTINS, O. B. A educação superior a distância e a democratização do saber. Petrópolis: Vozes, 1991.

MEDEIROS, M. F.de \& FARIA, E.T. Educação a distância: cartografias pulsantes em movimento. Porto Alegre: EDIPUCRS, 2003.

NEILL, A. S. Liberdade sem medo. 16.ed. São Paulo: IBRASA, 1976.

OLIVEIRA, M. K. de Vygotsky: aprendizado e desenvolvimento: um processo sóciohistórico. 3. ed. São Paulo: Scipione, 1995.

PETERS, O. A educação a distância em transição. São Leopoldo: UNISINOS, 2001.

PETERS, O. Didática do ensino a distância. São Leopoldo: UNISINOS, 2001.

PIAGET, J. (org.) (1967). Lógica e conhecimento científico. vol. 1. Porto: Civilização, 1980.

PIAGET, J. (org.) (1967). Lógica e conhecimento científico. vol. 2. Porto: Civilização, 1981.

PIAGET, Jean. (1970). A epistemologia genética. São Paulo: Abril Cultural, pp. 1-64. (Col. Os Pensadores), 1978.

ROGERS, C. R. Tornar-se pessoa. 5. ed. São Paulo: Martins Fontes, 1997.

RUMBLE, G. A gestão dos sistemas de ensino a distância. Brasília: UnB/UNESCO, 2003. 
SKINNER, B. F. O mito da liberdade. 3. ed. São Paulo: Summus, 1983.

SKINNER, B. F. Walden II: uma sociedade do futuro. 2.ed. São Paulo: E.P.U, 1978.

TRIVIÑOS, A. N. da S. Introdução à pesquisa em ciências sociais: a pesquisa qualitativa em educação. São Paulo: Atlas, 1987.

VIGOTSKI, L. S.; LURIA, A. R.; LEONTIEV, A. N. Linguagem, desenvolvimento e aprendizagem. São Paulo: Ícone/EDUSP, 1988.

VYGOTSKI, L. S. Pensamiento y lenguaje. In VYGOTSKI, L. S. “Obras escogidas”. Tomo II. Madrid: MEC/Visor, 1993.

ZULIAN, Margaret Simone. Redes virtuais: formação de professores. Porto Alegre: Imprensa, 2003. 